\title{
MARCAS SOCIAIS DE NOSSOS TEMPOS: GENNERO, SEXUALIDADE E EDUCAÇÃO EM ÂMBITO ESCOLAR
}

\author{
MARCAS SOCIALES DE NUESTRO TIEMPO: GÉNERO, SEXUALIDADY \\ EDUCACIÓN EN EL ÁMBITO ESCOLAR
}

\author{
SOCIAL MARKS OF OUR TIMES: GENDER, SEXUALITY AND SCHOOL \\ EDUCATION
}

\author{
Cristiane de Assis LUCIFORA ${ }^{1}$ \\ Fábio Tadeu REINA ${ }^{2}$ \\ Luci Regina MUZZETI ${ }^{3}$ \\ Renan Antônio da SILVA ${ }^{4}$
}

RESUMO: Este artigo teve como ponto de partida um capítulo da Dissertação de Mestrado intitulada "A reprodução das desigualdades de gênero nos contos de fadas/maravilhosos como marcas circunscritas na Educação Infantil" defendida em fevereiro de 2017 sobre a problematização dos papéis sociais atribuídos ao sexo de nascimento dos sujeitos e às diversas construções atribuídas como inerentes fazendo-se presentes em diversos âmbitos dentre eles o escolar. O campo teórico que embasou a pesquisa empreendida no mestrado e que se faz presente neste artigo é a Teoria Crítica, tendo como principal teórico Pierre Bourdieu e suas categorias de análise. Este artigo apresenta-se assim como uma estratégia teórica reflexiva sobre o quanto as desigualdades de gênero ainda se fazem presente e que a ideia de superação muitas vezes reforça a ideia de que as oportunidades são para todos e que muitos não estão presentes porque não querem ou se esforçam suficiente.

PALAVRAS-CHAVE: Gênero. Sexualidade. Educação.

RESUMEN: El artículo tuvo como punto de partida un capítulo de la Disertación de Maestría titulada "La reproducción de las desigualdades de género en los cuentos de hadas/maravillosos como marcas circunstanciales en la Enseñanza Infantil" defendida en febrero de 2017 sobre la problematización de los papeles sociales atribuidos al sexo de nacimientos de los sujetos y a las diversas construcciones atribuidas como inherentes poniéndose presentes en diversos ámbitos entre ellos el escolar. El campo teórico que basó la investigación emprendida en la maestría, y que se pone presente en este artículo es la Teoría Crítica, teniendo como principal

${ }^{1}$ Universidade Estadual Paulista (UNESP), Araraquara - SP - Brasil. Professora de Educação Infantil na rede municipal de ensino em São Carlos/SP. Doutoranda em Educação Escolar. ORCID: <http://orcid.org/0000-00028937-6412. E-mail: cristiane_pbf1@yahoo.com.br

2 Universidade Estadual Paulista (UNESP), Araraquara - SP - Brasil. Docente Colaborador. ORCID: $<$ http://orcid.org/ 0000-0002-2591-2378>. E-mail: ftreina@hotmail.com

${ }^{3}$ Universidade Estadual Paulista (UNESP), Araraquara - SP - Brasil. Professora assistente-doutora. Professora da Pós-graduação em Educação Escolar e integrante do Núcleo de Estudos da Sexualidade - NUSEX. ORCID: $<$ http://orcid.org/0000-0002-6808-2490>. E-mail: luci.muzzeti@unesp.br

${ }^{4}$ Universidade Estadual Paulista (UNESP), Marília - SP - Brasil. Docente Colaborador - PPG em Ciências Sociais. Pós-Doutorando em Ciências Sociais Educação Escolar pela UNESP/Araraquara. ORCID: < http://orcid.org/00000003-1171-217X>. E-mail: r.silva@unesp.br

RIAEE - Revista Ibero-Americana de Estudos em Educação, Araraquara, v. 14, n. esp. 2, p. 1395-1409, jul., 2019. E-ISSN: $1982-5587$. 
teórico Pierre Bordieu y sus categorías de análisis. Este artículo se presenta así como una estrategia reflexiva sobre cómo las desigualdades de género todavía se ponen presentes y que la idea de superación muchas veces refuerza la idea de que las oportunidades son para todos y que muchos no están presentes porque no quieren o no se esfuerzan lo suficiente.

PALABRAS CLAVE: Género. Sexualidad. Educación.

ABSTRACT: This article had as its starting point a chapter of the Master Dissertation entitled "The reproduction of gender inequalities in marvelous fairy tales as circumscribed marks in Pré-school Education" defended in February 2017 on the problematization of the social roles attributed to the gender of the birth of the subjects and the various constructions attributed as inherent, being present in several areas, among them the school. The theoretical field that underlies the research undertaken in the master's degree and that is present in this article is the Critical Theory having as main theoretical Pierre Bourdieu and its categories of analysis. This article presents as a theoretical reflexive strategy on how much gender inequalities are still present and that the idea of overcoming often reinforces the idea that opportunities are for everyone and that many are not present because they do not want or strive hard enough.

KEYWORDS: Gender. Sexuality. Education.

\section{Introdução}

Este artigo reflete sobre como as desigualdades de gênero se reinventam social e culturalmente de forma que muitas vezes assumem estratégias ideológicas tão fortes que impossibilitam seu reconhecimento facilmente. Temos no contexto brasileiro desequilíbrios econômicos, sociais e culturais ainda muito fortes e nos quais pesa um discurso neoliberal muito forte semeando o discurso de igualdade de oportunidade para todos e fortalecendo a ideia de que os excluídos os são por não se esforçarem suficiente.

Estudos na área da educação, cultura e sociedade apontam um contexto desigual no Brasil, no que diz respeito às relações entre os gêneros e, que se iniciando na formação familiar, acaba avançando por diversas outras instituições como escola, igreja, hospital, mídia etc., que seguem podando relações mais justas e igualitárias entre os diferentes sujeitos.

Gonini e Ribeiro (2014) nos aponta na historiografia da Educação Sexual no Brasil que pesa sobre as relações neste contexto um machismo exacerbado e naturalização da submissão feminina. É possível reconhecer diversas formas de subjugação das mulheres, o que eclode em uma alta taxa de violência contra a mulher e diversas justificativas sociais como se estas fossem merecedoras de tal violência. Muitas são as notícias diárias de mulheres sofrendo abusos sexuais por estranhos e parentes, sendo agredidas por seus parceiros ou por dizerem um não 
para um homem, pelo que vestem, pelo trabalho que exercem e diversos outros motivos que as colocam em situação de insegurança e sofrimento.

Segundo Gonini e Ribeiro (2014)

A contextualização histórica das atitudes sexuais pode explicar a institucionalização dos valores sexuais e do discurso pró ou antissexual, assim como a construção das representações do pensamento sexual contemporâneo em nossa sociedade (p. 266).

É necessário refletir sobre as bases que ancoram este contexto sexista e dessa forma clarificar as construções simbólicas marcadas pelo sexo dos sujeitos, que seguem como arbitrárias ao longo de suas vidas. Homens e mulheres são construídos de forma distintas desde que são reconhecidos enquanto sexo; as construções são reforçadas ao longo da vida, formando um reconhecimento social e uma naturalização com uma delimitação muito bem definida.

Segundo Louro (2008)

Gênero e sexualidade são construídos através de inúmeras aprendizagens e práticas, empreendidas por um conjunto inesgotável de instâncias sociais e culturais, de modo explícito ou dissimulado, num processo sempre inacabado. Na contemporaneidade, essas instâncias multiplicaram-se e seus ditames são, muitas vezes, distintos. Nesse embate cultural, torna-se necessário observar os modos como se constrói e se reconstrói a posição de normalidade e a posição da diferença, e os significados que lhes são atribuídos (p. 17).

A ideologia dominante cuida de naturalizar as relações como se estas fossem organicamente distintas entre homens e mulheres; aquilo que por força de uma manutenção social iniciada na família e reforçada por outras instituições mantêm-se ao longo da história e na cultura como um dado biológico inerente aos indivíduos.

Segundo Gomes (2006):

Nesse sentido, cabe enfatizar que a perpetuação da ordem dos gêneros esteve, até bem pouco tempo, garantida fundamentalmente pela ação conjunta de instituições como a família, a igreja, a escola e o Estado, sobre estruturas inconscientes. Todavia, é a família que tem o papel mais relevante na reprodução da dominação masculina, pois é no ambiente familiar que a criança, desde a mais tenra idade, vai interiorizando divisão sexual do trabalho e, consequentemente, os estereótipos vão sendo inculcados sob a forma de habitus primários (p. 36).

Gomes (2006) assume Habitus como o aprendizado que ocorre desde os primeiros momentos da vida, podendo iniciar-se antes mesmo do nascimento do sujeito, com as aspirações sociais que se formam partindo da descoberta do sexo do bebê. A instituição familiar com seus valores e crenças constroem comportamentos positivos e negativos desde a primeira 
infância, utilizando-se de meios sutis e refinados nas naturalizações que impregnam o habitus primário.

Para Louro (2008)

A construção dos gêneros e das sexualidades dá-se através de inúmeras aprendizagens e práticas, insinua-se nas mais distintas situações, é empreendida de modo explícito ou dissimulado por um conjunto inesgotável de instâncias sociais e culturais. É um processo minucioso, sutil, sempre inacabado (p. 18).

O gênero compreendido como conjunto de caracteres simbólicos que permeiam o imaginário social voltado para formas de ser, estar e agir de homens e mulheres, foge da ideia de que são fruto de condicionamentos biológicos. A formação do gênero inicia-se no contexto familiar, mas avança para outras instituições. Os sujeitos internalizam nos convívios sociais representações de masculinidades e feminilidades e compreendem mesmo que de forma inconsciente como enquadrar-se na heteronormatividade. A família inculca desde muito cedo formas consideradas normais de agir em sociedade e repreende aquilo que é visto como um desvio.

Segundo Bourdieu (2014):

As divisões constitutivas da ordem social e, mais precisamente, as relações sociais de dominação e de exploração que estão instituídas entre os gêneros se inscrevem, assim, progressivamente, em duas classes de habitus diferentes, sob a forma de hexis corporais opostos e complementares e de princípios de visão e de divisão, que levam a classificar todas as coisas do mundo e todas as práticas segundo distinções redutíveis à oposição entre o masculino e o feminino (p. 49).

Muitas são as facetas das desigualdades de gênero e estas contam com diversos meios de propagação dos ideais de divisão cultural e social entre homens/meninos e mulheres/meninas, sendo estes reconfigurados na sociedade; vemos na atualidade a grande influência midiática e dos meios eletrônicos como smartphones, internet e a publicidade, que reinventam as formas de propagação da desigualdade e muitas vezes dão um ar de superação, apontando para um poder feminino que está longe de ser alcançado plenamente.

Segundo Catonné (2001)

O triunfalismo não se justifica, porém. As feministas lúcidas constatam que a igualdade contraceptiva não foi acompanhada de uma emancipação econômica e social completa. Resumindo, a diferença global dos salários masculinos e femininos é de $1 / 3$; todo setor de atividade que se feminiza tende a se desvalorizar. Continua-se a opor um trabalho assalariado, primeiramente masculino, e uma atividade doméstica essencialmente feminina (p. 84). 
Nosso contexto atual aponta um processo de ruptura com muitas ideias vistas como arcaicas, motivadas por lutas históricas de movimentos sociais como o feminista, que reivindicaram uma participação da mulher em locais onde há pouco tempo the era negada. As mulheres se viram em uma participação maior na sociedade e reconfiguração do que é assumido como feminino, criou-se uma falsa ideia de que a igualdade entre os sexos foi conquistada por completo e aumentou de certa forma a identificação de tais desigualdades, que foram reveladas por diversos meios.

Ruth Sabat (2001) chama atenção para o poder que a publicidade tem em subverter os padrões estabelecidos não com fins de contestação, mas sim como maneira de chamar atenção para o produto que está à venda. Temos o caso recente da marca famosa de departamento que em uma propaganda coloca homens e mulheres mesclando figurinos masculinos e femininos, dando a entender que as pessoas não precisam se vestir de uma forma específica, mas sim conforme o gosto ou ousando. A propaganda em questão foi alvo de críticas por segmentos tradicionais da sociedade que defenderam ser uma subversão do que biologicamente é para cada sexo e que a vestimenta de homens e mulheres tem que ser diferente.

Segundo Sabat (2001):

Ao utilizar essas estratégias como forma de atingir consumidoras/es, a publicidade está trabalhando a partir de um currículo cultural que é constituído nas relações sociais e que opera como constituidor dessas mesmas relações. Tal currículo cultural faz parte de uma pedagogia específica, composta por um repertório de significados que, por sua vez, constroem e constituem identidades culturais hegemônicas (p. 14)

A princípio podemos ver essas iniciativas como uma proposta de ruptura com divisões fixas de gênero, porém temos que levar a crítica mais adiante e refletirmos se a mídia, ao propor uma subversão dos padrões arraigados, não o faz como contestação, mas sim como forma de chamar atenção do cliente para o produto que se quer vender.

Se sairmos deste binarismo que limita os sexos, as discussões são ainda mais complexas e repletas de tabus e segredos, de forma que os sujeitos que fogem às "regras" reservadas para o sexo que nasceram sofrem diversas represálias em uma sociedade que estigmatiza os desviantes da dita normalidade heterossexual.

Segundo Leite (2012)

Assim, os 'gêneros inteligíveis', que funcionam predominantemente ainda hoje, se organizam segundo a lógica do 'tem pênis, logo é homem, masculino e deve sentir atração afetivo-sexual por mulheres (é heterossexual)', e 'tem 
vagina, logo é mulher, feminina e deve sentir atração afetivo-sexual por homens', nesse campo, tanto pessoas homossexuais, bissexuais, quanto intersexuais, travestis, transexuais e todas aquelas que quebram essa pressuposta continuidade podem ser consideradas abjetas. (p. 561).

Os diversos campos atuam como mecanismos repressores de possíveis "desvios" presentes na sexualidade e gênero dos sujeitos. Aqueles que ousam atravessar as fronteiras voltadas para identidades fixas são na maioria das vezes recriminados pelo grupo. Ao mesmo tempo que os sujeitos são modelados para atender certas expectativas eles também são repelidos quando destoam, para que compreendam que ser "diferente" os afasta das pessoas assumidas como "normais".

A sexualidade humana acompanha a expectativa binária antes mesmo do sujeito romper com a vida intrauterina; a pergunta que acompanha o ser em gestação é qual o sexo deste e qual nome será dado, seguindo assim todo um universo representacional de cores, brinquedos, preparação para o quarto, etc., pensados para aquele sexo, e dessa forma todo um universo simbólico é colocado em prática para reforçar aquilo que se assume seja ligado a determinado sexo.

Cito uma prática chamada "chá de revelação", que pode ser assumida na atualidade como um rito de passagem onde tal simbolismo se mostra presente. A grávida convida um grupo, de familiares e amigos, para que nessa reunião possa ser anunciado o sexo do bebê, e nesta reunião são colocados enfeites simbolizando o masculino, abusando da cor azul, e o feminino, com cores rosas. Em certa altura de tal reunião a grávida através de algo também simbólico anuncia para os convidados qual o sexo do bebê; bexigas da cor azul ou rosa saindo do carro, o bolo que é pego na hora da anunciação em azul ou rosa. O simbólico toma conta do não dito e inicia toda representação generificada por indivíduos que serão marcados por diferenças assumidas como inerentes e não construídas.

O chá de revelação é um exemplo válido para compreender esse mundo simbólico que acompanha a descoberta do sexo e também para que se faça a crítica sobre o quanto esse binarismo de gênero ainda se faz presente em nosso contexto social. Há quem olhe de um dado ângulo e acredite que na atualidade esse binarismo esteja superado ou que ele não implique uma desigualdade entre os gêneros, contudo vemos com práticas como essa uma consagração de um universo que espera-se ser diferente e no qual haverá separações que poderão limitar em qual lado o sujeito estiver.

Ainda nos dias de hoje vemos que ao levarmos a discussão de gênero para as instituições escolares temos na maioria das vezes dois tipos de posicionamento, o estranhamento de um 
assunto que para muitos profissionais da educação não é adequado a este contexto e que portanto deve ser evitado ou o discurso de que as possíveis normas de gênero foram quase superadas gerando pouco ou quase nada de práticas que elevam uma categoria de gênero sobre a outra.

A sexualidade é assumidamente um tabu no contexto brasileiro, no qual os sujeitos em sua maioria não se sentem à vontade para dialogar sobre ela e em muitas situações é confundida com ato sexual, o que fere o pudor, fruto de nossas raízes cristãs que relegam os assuntos sexuais para o âmbito privado.

Discutir sexualidade não é algo fácil para todos, já que no imaginário social a ideia de que falar sobre isso é algo vergonhoso se faz presente. Desta forma, os sujeitos presentes em uma dada instituição carregam para esta esfera suas concepções sobre manifestações sexuais e com isso, nas suas relações com os demais sujeitos, deixam "escapar" por meio de suas ações tais concepções.

Professores vão para o campus escolar com os ideais construídos ao longo de sua vida e nas relações com os estudantes e corpo de funcionários empreendem uma transmissão dessas construções; pode ser ensinando conteúdos, em conversas descontraídas, no que interfere ou ignora, na presença do que tolera ou repreende, etc. O juizo professoral de forma subjetiva, qualifica e desqualifica determinadas características manifestas pelo corpo discente e com isso auxilia na propagação do que é assumido como "certo" e "normal" socialmente.

A Educação Infantil, que compreende a educação de crianças de 0 a 5 anos, é um campus no qual faz-se ainda mais complicado a inserção de trabalhos voltados para a Educação Sexual, já que em tal universo a criança é vista como aquela que não possui sexualidade e que trabalhos com gênero poderiam prejudicar a formação da identidade de tais crianças.

As diretrizes Curriculares Nacionais da Educação Infantil (DCNEI) e os Referenciais Curriculares Nacionais para a Educação Infantil (RCNEI) definem a faixa etária de 0 a 5 anos como as atendidas pela Educação Infantil, sendo essa assumida como primeira etapa da educação básica. É oferecida em creches e pré-escolas caracterizando-se esses como espaços institucionais não familiares, que podem ser públicos ou privados e que educam e cuidam das crianças no período diurno, em jornada integral ou parcial. Esses espaços são regulados e supervisionados por órgão competente do sistema de ensino e submetidos a controle social.

Segundo Figueiró (2013):

Com relação à Educação Infantil, existem os Referenciais Curriculares Infantis (RCI), que, embora não apresentem diretamente uma proposta de 
ensino do tema sexualidade, trazem vários pontos dentro do conteúdo programático que dão margem ao ensino sobre corpo, gênero e todas as demais temáticas que a professora preparada e sensível conseguirá inserir (p. 107).

Reflito sobre a dificuldade de se inserir a problemática de gênero e sexualidade na escola, por haver uma preocupação que tais assuntos devam ser problematizados pela família, mas que na verdade esses façam-se presentes através de representações que os sujeitos carregam em sua própria formação identitária. A escola não é neutra e ao se colocar assim contribui para que muitos ideais excludentes sejam reproduzidos de forma naturalizada.

Assim, a violência simbólica inscrita na "ordem das coisas" avança sem chamar atenção ao longo da vida dos sujeitos nos diversos meios onde este passa, como conjunto de caracteres que se colocam com aparência de neutralidade e arbitrariedade. Segundo Bourdieu (2014):

A dominação masculina encontra assim reunidas todas as condições de seu pleno exercício. A primazia universalmente concedida aos homens se afirma na objetividade de estruturas sociais e de atividades produtivas, baseadas em uma divisão sexual do trabalho de produção e de reprodução biológica e social, que confere aos homens a melhor parte, bem como nos esquemas imanentes a todos os habitus moldados por tais condições, portanto objetivamente concordes, eles funcionam como matrizes das percepções, dos pensamentos e das ações de todos os membros da sociedade, como transcendentais históricos que, sendo universalmente partilhados, impõem-se a cada agente como transcendentes (p. 54).

A violência simbólica também tem fortes laços com a linguagem, que auxilia na instituição dos sujeitos, delimitando os lugares nos quais estes transitam e respondem a determinadas ações. A linguagem por ocorrer de forma simples nas diversas relações humanas têm por trás de si diversos mecanismos de poder que passam despercebidos.

Muitos profissionais da educação buscam não se comprometer com as problemáticas de gênero e sexualidade, e quando tais questões entram no universo da educação infantil são limitados por manifestações incrédulas de que as crianças seriam capazes de compreender e refletir sobre tais assuntos. Em um processo de identificação sobre a reprodução das desigualdades de gênero compreende-se a necessidade de reconhecimento sobre os ideais de criança e infância que permeiam o imaginário dos educadores e que acabam influenciando as práticas pedagógicas.

Segundo Nunes e Silva (2006):

A aquisição da linguagem, a imposição dos papéis sexuais, a cristalização dos comportamentos disciplinares e capacidade de produção são os principais elementos do ethos educacional que construímos e continuamente reproduzimos. Retrato exemplar desta realidade é a curiosa e frequente 
indagação que fazemos às nossas crianças ' $O$ que você vai ser quando crescer? (p. 10).

Deste modo a criança é assumida como um ser inocente e no qual cabe os investimentos para o adulto que será potencialmente, entretanto tem parte de si oculta como algo não pertencente a sua natureza. A sexualidade presente na formação de sua identidade é inculcada como algo que se deva ocultar reforçando a ideia de que essa é vergonhosa.

Para Nunes e Silva (2006, p. 13), “a Educação Sexual escolar sempre foi objeto de polêmica em nossa tradição educacional. A escola brasileira, pública e privada, sempre manteve este tema distante de seus procedimentos curriculares e responsabilidades institucionais".

Compreender a ação pedagógica como fenômeno político e ideológico requer a compreensão de que todo sujeito social carrega em si as marcas da construção de sua trajetória pessoal e profissional, sendo estas marcadas por rupturas excludentes ou não que se inserem nas diversas relações estabelecidas entre os diversos sujeitos.

Uma das discussões possíveis é o que é assumido/considerado cultura e sua repercussão social para sancionar o que é tomado como digno de valor ou não. $O$ conceito de cultura pautase no conceito antropológico que vê a cultura como interpretação da vida social, maneira dos sujeitos viverem e se organizarem socialmente, maneira de viver de determinados grupos, sociedade, país ou pessoas; códigos que são assumidos de forma grupal, tendo um representacional de como pensam, classificam, agem, estudam e modificam seu redor e a si mesmos. São sujeitos que compartilham os mesmos objetos, tendo na maioria vezes grupos formados pelo seguimento de certas normas e objetivos.

Segundo Candau (2008):

As nossas maneiras de situarmo-nos em relação aos outros tende "naturalmente", isto é, estão construídas, a partir de uma perspectiva etnocêntrica. Incluímos na categoria "nós", em geral, aquelas pessoas e grupos sociais que têm referenciais culturais e sociais semelhantes aos nossos, que têm hábitos de vida, valores, estilos, visões de mundo que se aproximavam dos nossos e os reforçam (p. 29).

O determinismo biológico foi e é utilizado como estratégia discursiva e ideológica na concepção do que é considerado naturalmente feminino e naturalmente masculino, marcado por diversas características assumidas no âmbito cultural como sendo da natureza de cada sexo. A cultura sanciona o que é valorativo e por inúmeros processos de inculcamento faz com que pareça inerente e biológico a cada indivíduo e não como formação social.

Laraia (1999) aponta: 
A espécie humana se diferencia anatômica e fisiologicamente através do dimorfismo sexual, mas é falso que as diferenças de comportamento existentes entre pessoas de sexos diferentes sejam determinadas biologicamente. A antropologia tem demonstrado que muitas atividades atribuídas às mulheres em uma cultura podem ser atribuídas aos homens em outras (p. 19).

A construção dos sujeitos por gênero é marcada por diferenças que são apreendidas no seio da cultura e que são marcadas por relações assumidas como naturais e presentes no cerne de tais sujeitos. Representam formas de portar-se conforme o que se espera para cada sexo, conjunto de caracteres que cristalizados na sociedade seguem como inerentes.

Aponta (Laraia, 1999)

Resumindo, o comportamento dos indivíduos depende de um aprendizado, de um processo que chamamos de endoculturação. Um menino e uma menina agem diferentemente não em função de seus hormônios, mas em decorrência de uma educação diferenciada (p. 20).

A educação auxilia na inculcação dos comportamentos diferenciados, tanto em meio escolar quanto na socialização familiar exterior a tal instituição. Os sujeitos aprendem a portarse da forma como socialmente serão aceitos e tal aprendizado na maioria das vezes não se dá de forma consciente.

Para Laraia (1999)

O modo de ver o mundo, as apreciações de ordem moral e valorativa, os diferentes comportamentos sociais e mesmo as posturas corporais são assim produtos de uma herança cultural, ou seja, o resultado da operação de uma determinada cultura (p. 70).

Vemos no contexto contemporâneo brasileiro uma corrente forte voltada para o abafamento do trabalho com o gênero e sexualidade, com a justificativa de que o trabalho com tais questões feriria o direito familiar de decidir o que seu filho pode ou não saber e também que problematizar tais questões poderia estimular o interesse por assuntos que sem a informação não surgiriam naquele momento, e também o interesse por formas de se relacionar como o homoerotismo que sairiam do contexto entendido como normalidade, que é a heteronormatividade.

Muito é deixado de fora neste contexto, já que ao se continuar assumindo uma forma de relacionar-se como natural e normativa exclui-se as manifestações que divergem. Isso se dá também no terreno externo à sexualidade e visível nas relações de gênero como diferentes formas de manifestar a feminilidade e a masculinidade. Intensifica-se a ideia que os sujeitos têm que atender a determinadas características e que fora destas sofrerão para serem aceitos em RIAEE - Revista Ibero-Americana de Estudos em Educação, Araraquara, v. 14, n. esp. 2, p. 1395-1409, jul., 2019. E-ISSN: $1982-5587$. 
suas diferenças.

Furlani (2011) problematiza que uma das vertentes que manifesta a sexualidade com aspectos normativos é a abordagem terapêutica que segue uma interpretação da bíblia literal, sendo ela o requisito para referendar a ética moral. Os sujeitos que seguem tal vertente abominam sexualidades que desviam da norma e acreditam inclusive que por terapia pode-se curar tais desvios. Segundo (Furlani, 2011, p. 21), "o uso literal da bíblia tem sido usado, hoje, nas investidas pela manutenção da família patriarcal e pela volta da "submissão" da mulher, tal como se dava nos tempos remotos das antigas escrituras".

O Brasil é fortemente marcado pela tradição católica e esta impregna o imaginário social com ações que naturalizadas seguem como inerentes aos seres humanos. As condutas são marcadas por ideais voltados para o feminino e masculino e configurações familiares. Os professores presentes nessa cultura e tendo seu habitus construído nas relações estabelecidas nos seios institucionais levam tal repertório para sua ação pedagógica, mesmo na atualidade a escola sendo laica.

Gomes (2006):
A igreja contribui apregoando uma moral antifeminista, fundamentada em valores patriarcais, mas, principalmente por meio da crença na inata inferioridade feminina. A escola, mesmo libertada da influência da Igreja, colabora com a reprodução de estereótipos ao fundamentar-se na representação patriarcal, que mantém uma estrutura hierárquica com forte conotação sexuada, fazendo do homem o princípio ativo e, da mulher, o passivo (p. 36).

A mulher nessa tradição é assumida como o homem não desenvolvido, sendo aquela que nasceu de sua costela para ser sua companheira e que posteriormente por sua ambição demasiada foi responsável pela expulsão do paraíso, devendo-lhe assim submissão e subserviência. Ainda que atualmente a tradição católica venha se reinventando historicamente no Brasil, muito de seus valores e morais se dão de forma cristalizada na sociedade e se veem fortalecida pela ideia que naturalmente homens e mulheres são diferentes, visualizando assim as desigualdades entre estes como uma consequência das limitações de cada gênero.

Laraia (1999) nos chama atenção para a reflexão de que muito do que se compreende como inerente à natureza dos indivíduos, na verdade é fruto de procedimentos culturais que não estão associados com uma ordem objetiva, mas como efeito de condicionamentos culturais. Justificativas de cunho biológico sempre se fizeram presente na história da sexualidade e muitas vezes serviram para afirmar e reforçar as desigualdades entre homens e mulheres. Muitos são os motivadores de discursos de reafirmação da desigualdade profissional entre os sexos por RIAEE - Revista Ibero-Americana de Estudos em Educação, Araraquara, v. 14, n. esp. 2, p. 1395-1409, jul., 2019. E-ISSN: $1982-5587$. 
pautar-se na ideia de que os homens têm mais força ou a mulher mais jeito maternal e cuidadoso, que os homens não se afastam pela e para a maternidade, mas que as mulheres sim, o que justifica estas receberem menos porque os custeios com tal benefício são onerosos para o empregador e, o que nos dias de hoje tem menos força, a justificativa de que o intelecto do homem é mais aprimorado do que o das mulheres, o que faz com que os trabalhos "menos dignos" sejam reservado à categoria feminina sem quase prestígio social e econômico algum, e no qual é muitas vezes visto como complementação financeira do salário principal de quem assume o lar, que é o homem.

Os mecanismos ideológicos que diferenciam a participação política entre homens e mulheres reafirmam a pseudonormalidade dos homens estarem mais presentes neste meio, cria um abismo ainda maior para as mulheres que lutam por maior participação nos diversos espaços.

Laraia (1999) aponta:

O tempo constitui um elemento importante na análise de uma cultura. Nesse mesmo quarto de século, mudaram-se os padrões de beleza. Regras morais que eram vigentes passaram a ser consideradas nulas: hoje uma jovem pode fumar em público sem que sua reputação seja ferida. Ao contrário de sua mãe, pode ceder um beijo ao namorado em plena luz do dia. Tais fatos atestam que mudanças de costumes são bastantes comuns. Entretanto, elas não ocorrem com a tranquilidade que descrevemos. Cada mudança, por menor que seja, representa o desenlace de numerosos conflitos. Isto porque em cada momento as sociedades humanas são palco do embate entre as tendências conservadoras e inovadoras (p. 103).

Tal autor aponta que o sistema social está sempre em transformação, mesmo que de forma lenta.

Macedo (2010) reflete sobre a construção histórica do que se coloca como uma cultura universal, tendo tal universalidade garantida por mecanismos políticos e econômicos poderosos, garantidos pela expansão colonial da Europa pelo mundo. Tal cultura se expandia com ideais civilizadores. Segundo Macedo (2010):

Por experiência, percebemos que a cultura universal, ou mesmo a cultura nacional, conviveu com o apagamento de muitas manifestações culturais de grupos minoritários que viviam em seu interior. Ainda assim, não se trata de uma questão resolvida (p. 14).

O que se percebe em jogo no que diz respeito às desigualdades de gênero é que, motivado por lutas históricas de movimentos, como o feminismo, as mulheres adentraram em contextos que até bem pouco tempo eram reservados apenas aos homens, mas tal entrada ainda 
encontra-se subordinada a ditames que consagram o homem como aquele que lidera e ao qual o poder lhe é inerente. As mulheres viram suas configurações alterarem-se da "confinação" do lar para a entrada no mundo do trabalho, porém o fenômeno social que se consagra é a dupla função no qual muitas mulheres viram-se inseridas sem a participação efetiva masculina. Os homens em sua maioria não mudaram suas mentalidades, compreendendo a obrigação dos afazeres domésticos como pertencentes às mulheres e entendendo que quando participam destes estão auxiliando e não trabalhando junto.

Segundo Da Silva, 2005:

O que a análise feminista vai questionar é precisamente essa aparente neutralidade - em termos de gênero - do mundo social. A sociedade está feita de acordo com as características do gênero dominante, isto é, o masculino (p. 93).

As instituições, como refletido anteriormente, continuam reproduzindo ideais desiguais entre os sexos e de certa forma sem seus participantes pensarem criticamente sobre a influência de tal reprodução. A escola neste contexto atual continua operando através do currículo, ritos e ações dos seus agentes características diferentes para meninos e meninas. Tais operações precisam passar pelo crivo crítico e político que a ação pedagógica possa ter na formação das identidades dos agentes que lá estão sendo construídos (crianças) por agentes impregnados de valores construídos em sua trajetória pessoal e profissional (professores) de forma que esses reflitam sobre os conteúdos ensinados e as ações que se estabelecem em meio pedagógico.

Todo conhecimento colocado em prática em meio escolar e as ações empreendidas nas relações estabelecidas são sujeitas a relações de poder que refletem os lugares ocupados pelos sujeitos, nível de influência, formas de se manifestar ou não, etc.

Segundo Louro (2008)

Continuamente, as marcas da diferença são inscritas e reinscritas pelas políticas e pelos saberes legitimados, reiteradas por variadas práticas sociais e pedagogias culturais. Se, hoje, as classificações binárias dos gêneros e da sexualidade não mais dão conta das possibilidades de práticas e de identidades, isso não significa que os sujeitos transitem livremente entre esses territórios, isso não significa que eles e elas sejam igualmente considerados (p. 22).

A instituição escolar imersa em um contexto em transformação precisa que os responsáveis pelo ensino pensem criticamente no conteúdo que transmitem e o quanto historicamente tais conteúdos seguem uma lógica excludente para determinados grupos sociais. 


\section{REFERÊNCIAS}

BOURDIEU, Pierre. A dominação masculina: a condição feminina e a violência simbólica. Rio de Janeiro: BestBolso. 2014.

CANDAU, Vera Maria. Multiculturalismo e educação: desafios para a prática pedagógica. In: Multiculturalismo: diferenças culturais e práticas pedagógicas. Organização Antonio Flávio Moreira \& Vera Maria Candau. Petrópolis, RJ: Vozes, p. 13-66, 2008.

CATONNÉ, Jean-Philippe. A sexualidade, ontem e hoje. São Paulo: Cortez. 2001.

DA SILVA, Tomaz Tadeu. Documentos de identidade: uma introdução às teorias do currículo. Belo Horizonte: Autêntica Editora. 2005.

FIGUEIRÓ, Mary Neide Damico. Educação sexual no dia a dia. Londrina, PR: Eduel. 2013.

FURLANI, Jimena. Educação Sexual na sala de aula: relações de gênero, orientação sexual e igualdade étnico-racial numa proposta de respeito às diferenças. Belo Horizonte: Autêntica Editora. 2011.

GOMES, Vera Lúcia de Oliveira. A construção do feminino e do masculino no processo de cuidar crianças em pré-escolas. Texto \& Contexto-Enfermagem, v. 15, n. 1, p. 35-42, 2006.

GONINI, Fátima Aparecida Coelho; RIBEIRO, Paulo Rennes Marçal. A sexualidade e sua construção histórica: alguns apontamentos para educadores que trabalham com Educação Sexual. In: Miradas diversas de la educacion in Iberoamérica. Organização Jaboreno, M. Bucaramanga, Universidade Autónoma de Bucaramanga, p. 265-77, 2014.

LARAIA, Roque. Cultura: Um Conceito Antropológico. 12. ed. Rio de Janeiro: Jorge Zahar Editores Ltda. 1999.

LEITE JUNIOR, Jorge. Transitar para onde? Monstruosidade, (des)patologização, (in)segurança social e identidades transgêneras. Estudos Feministas, v. 20, n. 2, p. 559-568, 2012.

LOURO, Guacira Lopes. Gênero e Sexualidade: pedagogias contemporâneas. Pró-Posições. UFRG, v. 19, n. 2, p. 17-23, 2008.

MACEDO, Elizabeth. A Cultura e a Escola. In: MACEDO, Elizabeth. Marcas da diferença no ensino escolar. Organização Richard Miskolci. São Carlos, SP: EdUFSCar, p. 11-44, 2010 .

NUNES, César; SILVA, Edna. A educação sexual da criança: subsídios teóricos e propostas práticas para uma abordagem da sexualidade para além da transversalidade. 2. ed. Campinas, SP: Autores Associados. 2006.

SABAT, Ruth. Pedagogia Cultural, gênero e sexualidade. Estudos Feministas, Florianópolis, v. 9, n. 1, p. 9-21, 2001. 


\section{Como referenciar este artigo}

LUCIFORA, Cristiane de Assis; REINA, Fábio Tadeu; MUZZETI, Luci Regina; SILVA, Renan Antônio da. Marcas sociais de nossos tempos: gênero, sexualidade e educação em âmbito escolar. Revista Ibero-Americana de Estudos em Educação, Araraquara, v. 14, n. esp. 2, p. 1395-1409, jul., 2019. E-ISSN: 1982-5587. DOI: 10.21723/riaee.v14iesp.2.12607

Submetido em: 27/09/2018

Revisões requeridas: 22/02/2019

Aprovado em: 29/04/2019

Publicado em: 26/06/2019 